\title{
IMPROVEMENT OF THE K-PROFILE MODEL FOR THE PLANETARY BOUNDARY LAYER BASED ON LARGE EDDY SIMULATION DATA
}

\author{
Y. NOH ${ }^{\star}$, W. G. CHEON and S. Y. HONG \\ Department of Atmospheric Sciences, Yonsei University, 134 Shinchon-dong, Seodaemun-gu, Seoul \\ 120-749, Korea \\ S. RAASCH \\ Institute of Meteorology and Climatology, University of Hannover, Germany
}

(Received in final form 9 August 2002)

\begin{abstract}
Modifications of the widely used K-profile model of the planetary boundary layer (PBL), reported by Troen and Mahrt (TM) in 1986, are proposed and their effects examined by comparison with large eddy simulation (LES) data. The modifications involve three parts. First, the heat flux from the entrainment at the inversion layer is incorporated into the heat and momentum profiles, and it is used to predict the growth of the PBL directly. Second, profiles of the velocity scale and the Prandtl number in the PBL are proposed, in contrast to the constant values used in the TM model. Finally, non-local mixing of momentum was included. The results from the new PBL model and the original TM model are compared with LES data. The TM model was found to give too high PBL heights in the PBL with strong shear, and too low heights for the convection-dominated PBL, which causes unrealistic heat flux profiles. The new PBL model improves the predictability of the PBL height and produces profiles that are more realistic. Moreover, the new PBL model produces more realistic profiles of potential temperature and velocity. We also investigated how each of these three modifications affects the results, and found that explicit representation of the entrainment rate is the most critical.
\end{abstract}

Keywords: K-profile model, Large eddy simulation (LES), Non-local mixing, Planetary boundary layer (PBL), PBL model.

\section{Introduction}

The transport by large eddies plays an important role in the vertical mixing of heat, momentum and moisture in the convective boundary layer. The usual downgradient parameterization of vertical mixing is not appropriate in this case, and the non-local mixing associated with the bulk properties of the planetary boundary layer (PBL) has been increasingly applied (Deardorff, 1966; Therry and Lacarrere, 1983; Stull, 1984; Troen and Mahrt, 1986; Holtslag and Moeng, 1991; Chrobok et al., 1992; Abdella and McFarlane, 1997).

The inclusion of the effects of non-local mixing was pursued in various different ways. For example, Stull (1984) developed the transilient model in which various non-local mixings are explicitly treated, and Therry and Lacarrere (1983)

^ E-mail: noh@atmos.yonsei.ac.kr 
and Abdella and McFarlane (1997) included non-local terms in the second-order turbulence closure model. Meanwhile, Troen and Mahrt (1986) developed the Kprofile model in which the profiles of eddy diffusivity and viscosity are presumed a priori, based on the overall mixing property of the PBL.

In the Troen and Mahrt model (TM model, hereafter) the non-local mixing in the kinematic heat flux is represented by

$$
-\overline{w^{\prime} \theta^{\prime}}=K_{h}\left(\frac{\partial \theta}{\partial z}-\gamma_{h}\right)
$$

Here $K_{h}$ is the eddy diffusivity for potential temperature $\theta$ and $\gamma_{h}$ is the countergradient term representing the non-local mixing due to large convective eddies.

The TM model also assumes the profile of the eddy viscosity as

$$
K_{m}=k w_{s} z\left(1-\frac{z}{h}\right)^{2}
$$

where $k$ is the von Karman constant $(=0.4), z$ is the distance from the surface, and $h$ is the boundary-layer height. Note that in the TM model $h$ represents the height where the heat flux disappears, i.e., $\overline{w^{\prime} \theta^{\prime}}=0$ at $z=h$, which is located above the height of the minimum heat flux. The eddy diffusivity $K_{h}$ in (1) is computed from $K_{m}$ by using the Prandtl number $\mathrm{Pr}$, as $K_{h}=\mathrm{Pr}^{-1} K_{m}$.

The velocity scale $w_{s}$ in (2) is represented by the value scaled at the top of the surface layer, $w_{s 0}$ such as

$$
w_{s 0}=\left(u_{*}^{3}+7 \varepsilon k w_{*}^{3}\right)^{1 / 3},
$$

where

$$
w_{*}=\left[\left(g / T_{0}\right)\left(\overline{w^{\prime} \theta_{0}^{\prime}} h\right)\right]^{1 / 3}
$$

is the convective velocity scale given the surface buoyancy flux $\left(g / T_{0}\right) \overline{w^{\prime} \theta_{0}^{\prime}}$, and the ratio of the surface layer height to the PBL height, $\varepsilon$ is arbitrarily specified to be 0.1 .

Here the velocity scale $w_{s 0}$ is made to be coincident with the velocity scale at the top of the surface boundary layer $(z=\varepsilon h)$ as

$$
w_{s 0}=u_{*} \phi_{m}^{-1},
$$

where $u_{*}$ is the surface friction velocity and $\phi_{m}$ is the wind profile function evaluated at the top of the surface layer.

The value of $\phi_{m}$ is obtained by satisfying the compatibility with the surface boundary similarity. The profile functions for momentum and heat, $\phi_{m}$ and $\phi_{h}$, are given respectively by

$$
\phi_{m}=\phi_{h}=1+4.7 z / L
$$


for stable conditions, and

$$
\begin{aligned}
& \phi_{m}=(1-16 z / L)^{-1 / 4}, \\
& \phi_{h}=(1-16 z / L)^{-1 / 2},
\end{aligned}
$$

for unstable conditions, from Businger et al. (1971), where $L$ is the Obukhov length $\left(\equiv-u_{*}^{3} T_{0} / k g \overline{w^{\prime} \theta_{0}^{\prime}}\right)$. To determine (5) in unstable conditions, however, Troen and Mahrt (1986) assumed the following function;

$$
\phi_{m}=(1-7 z / L)^{-1 / 3} .
$$

The exponent of $-1 / 3$ in (9) was chosen to ensure the free-convection limit for $z \gg L$. With the coefficient chosen to be 7, the values obtained from (7) and (9) differ less than $6 \%$ for $z / L<2$. We can obtain the value of $w_{s 0}$, given by (3), by substituting (9) into (5).

The countergradient term $\gamma_{h}$ in (1) is given by

$$
\gamma_{h}=b_{0} \frac{\overline{w^{\prime} \theta_{0}^{\prime}}}{w_{s 0} h}
$$

where $b_{0}$ is a coefficient of proportionality. Troen and Mahrt (1986) suggested the value of this coefficient as $b_{0}=6.5$.

The boundary-layer height is determined by specifying a critical value of the bulk Richardson number $R i_{b}$ defined by

$$
h=R i_{b} \frac{T_{0}|\mathbf{U}(h)|^{2}}{g\left(\theta(h)-\theta_{s}\right)},
$$

where $\mathbf{U}(h)$ and $\theta(h)$ are the horizontal wind speed and the potential temperature at $z=h$. The temperature scale of the boundary layer $\theta_{s}$ is defined as

$$
\theta_{s}=\theta\left(z_{1}\right)+\theta_{T}
$$

with

$$
\theta_{T}=b_{0} \frac{\overline{w^{\prime} \theta_{0}^{\prime}}}{w_{s 0}} .
$$

Here $\theta\left(z_{1}\right)$ is the potential temperature at the lowest atmospheric level in the model $z_{1}$. For the critical value of the bulk Richardson number, $R i_{b}=0.5$ was suggested.

For the actual prediction of the growth of $h$ in the TM model, the criterion (11) can be rewritten as

$$
\theta(h)=\theta_{s}+R i_{b} \frac{T_{0}|\mathbf{U}(h)|^{2}}{g h},
$$


Using (14), $h$ is determined at each time step, after the potential temperature profile is modified by the vertical diffusion given by (1).

The Prandtl number is given by the value $P r_{0}$ obtained at the top of the surface layer $(z=\varepsilon h)$ as (Troen and Mahrt, 1986),

$$
\operatorname{Pr}_{0}=\frac{\phi_{h}}{\phi_{m}}+b_{0} \varepsilon k \text {. }
$$

In the TM model the Prandtl number is assumed constant over the whole boundary layer.

The TM model has been applied to climate and weather forecast models (Hong and Pan, 1996; Holtslag and Boville, 1993; Lüpkes and Schlünzen, 1996), and it was found to improve the prediction of the PBL effectively by incorporating the non-local mixing, notwithstanding its relative simplicity. The results showed that the TM model can transport heat and moisture more effectively away from the surface compared to a local mixing model, and thus reproduces more realistic temperature and humidity profiles.

The performance of the TM model was examined recently using large eddy simulation (LES) data. Ayotte et al. (1996) evaluated the performance of various PBL models by comparing various integrated quantities from the models with those from LES. Although the TM model was found to perform better than other PBL models in general, its prediction of the entrainment rate is not satisfactory. In particular, it was found that the entrainment is overestimated for a PBL with strong shear and underestimated for free convection in the TM model. Meanwhile, Brown (1996) found that the TM model produces too strong shear within the convective boundary layer from examinations of mean temperature and velocity profiles obtained from LES, although the TM model still shows improved results compared to the local mixing scheme.

The above-mentioned investigations of the TM model using LES were mainly concerned with the mean variables such as potential temperature and velocity or the integrated properties. However, for more rigorous assessment of the validity of the model we also need to examine the various assumptions introduced into the TM model under various circumstances, such as the heat flux profile of (1) and the critical bulk Richardson number used to determine the boundary-layer height in (11).

Meanwhile, a few questions are raised with regard to the TM model from a theoretical viewpoint.

First, the entrainment is not represented explicitly in the heat flux profile, and the vertical mixing and the growth of the PBL are treated separately. This is rather absurd, considering that both the vertical mixing and the growth of the PBL represent the vertical heat transfer. They are usually treated simultaneously in turbulence closure models, e.g., the Mellor-Yamada model (Mellor and Yamada, 1982).

Second, the model is not consistent with the case of free convection. The Kprofile of (2) does not obey the free convection limit, $K_{h} \propto z^{4 / 3}$ for $z \ll h$ 
(Panofsky and Dutton, 1984), as pointed out by Holtslag and Moeng (1991). Furthermore, both the velocity scale and the Prandtl number $P r$, which are evaluated at the top of the surface layer by (3) and (15), are assumed to remain invariant throughout the PBL. However, the factors used to evaluate $w_{s}$ and $\operatorname{Pr}$, such as turbulent kinetic energy (TKE) and stability, vary substantially with height within the PBL.

Finally, it still needs to be determined whether we can really neglect the nonlocal mixing of momentum in the convective boundary layer, while the non-local mixing of heat is applied. Brown and Grant (1997) and Frech and Mahrt (1996) suggested the inclusion of the non-local mixing of momentum for more realistic prediction of the wind profile in the convective boundary layer. However, it is not yet clear how the inclusion of the non-local mixing of momentum can improve the general performance of a PBL model such as the growth of $h$.

In this paper, we suggested a new PBL model by modifying the TM model as to the above-mentioned three factors with the help of LES data. Having developed a new PBL model, we evaluated the performance of both TM model and the new PBL model by comparing the resultant various profiles and boundary-layer heights with the LES data. In addition, we analyzed how each of these three modifications in the new PBL model affects the results.

\section{LES Model and Simulations}

The various PBL flows used in this study were generated from the LES code described in Raasch and Etling (1991). Subgrid-scale turbulence is modelled according to Deardorff (1980). A prognostic equation is solved for the subgrid-scale TKE, which is used to parameterize the subgrid-scale fluxes. Between the surface and the first computational grid level Monin-Obukhov similarity is assumed. Periodic boundary conditions are used in both lateral directions. The present LES model has been successfully applied to various PBL problems (Raasch and Etling, 1998; Raasch and Harbusch, 2001; Schröter et al., 2000).

The numerical scheme is a standard, second-order finite difference scheme using the absolutely-conserving scheme of Piacsek and Williams (1970) for the nonlinear advection term. The prognostic equations are time-advanced by a leapfrog scheme. A weak time filter is applied to remove the time-splitting instability of the leapfrog method (Asselin, 1972). During the integration the time step is adjusted so that it never exceeds one tenth of the allowed value due to the CFL (Courant-Friedrichs-Lewy) and diffusion criteria. Incompressiblity is applied by means of the Poisson equation for pressure, which is solved by an FFT method. Recently the code has been parallelized, and the performance of the new parallellized code is found to be excellent on an SGI/Cray-T3E with an almost linear speed-up up to a very large number of processors (Raasch and Schröter, 2001). 
TABLE I

Parameters of large eddy simulations at $t=t_{0}+6000 \mathrm{~s}$.

\begin{tabular}{|c|c|c|c|c|c|}
\hline & $\begin{array}{l}\overline{\theta^{\prime} w_{0}^{\prime}} \\
\left(\mathrm{K} \mathrm{m} \mathrm{s}^{-1}\right)\end{array}$ & $\begin{array}{l}\mathbf{U}_{g} \\
\left(\mathrm{~m} \mathrm{~s}^{-1}\right)\end{array}$ & $\begin{array}{l}w_{*} \\
\left(\mathrm{~m} \mathrm{~s}^{-1}\right)\end{array}$ & $\begin{array}{l}u_{*} \\
\left(\mathrm{~m} \mathrm{~s}^{-1}\right)\end{array}$ & $\begin{array}{l}h \\
(\mathrm{~m})\end{array}$ \\
\hline A0 & 0.01 & 0.0 & 0.66 & 0.07 & 862.50 \\
\hline A1 & 0.01 & 5.0 & 0.66 & 0.27 & 862.50 \\
\hline A2 & 0.01 & 10.0 & 0.66 & 0.45 & 862.50 \\
\hline A3 & 0.01 & 15.0 & 0.66 & 0.62 & 881.25 \\
\hline B1 & 0.05 & 5.0 & 1.16 & 0.29 & 956.25 \\
\hline B2 & 0.05 & 10.0 & 1.16 & 0.45 & 956.25 \\
\hline B3 & 0.05 & 15.0 & 1.17 & 0.63 & 975.00 \\
\hline $\mathrm{C} 0$ & 0.24 & 0.0 & 2.13 & 0.21 & 1237.50 \\
\hline $\mathrm{C} 1$ & 0.24 & 5.0 & 2.12 & 0.34 & 1218.75 \\
\hline $\mathrm{C} 2$ & 0.24 & 10.0 & 2.12 & 0.53 & 1218.75 \\
\hline C3 & 0.24 & 15.0 & 2.14 & 0.69 & 1256.25 \\
\hline S & 0.0 & 10.0 & 0.0 & 0.47 & 843.75 \\
\hline
\end{tabular}

The model domain is $4 \mathrm{~km} \times 2 \mathrm{~km} \times 1.5 \mathrm{~km}$ along the $x, y$ and $z$ directions, respectively. The number of the corresponding grid points is $80 \times 80 \times 80$. During all model runs the initial temperature stratification was neutral up to $800 \mathrm{~m}$ and stable $\left(0.01 \mathrm{~K} \mathrm{~m}^{-1}\right)$ aloft, up to the top of the model domain, in order to allow rapid growth of the convective boundary layer at the beginning of the simulation. The boundary layer was heated by a constant uniform kinematic surface heat flux $\overline{w^{\prime} \theta_{0}^{\prime}}$. A constant large-scale pressure gradient corresponding to a geostrophic wind in the x-direction $U_{g}$ was applied. The Coriolis force corresponds to the latitude of $40^{\circ} \mathrm{N}$. The horizontal velocity fields were perturbed every minute by imposing small random perturbations to initiate convection until the kinetic energy of the disturbances reached the value of $0.01 \mathrm{~m}^{2} \mathrm{~s}^{-2}$.

A total of 12 simulations were carried out for the analysis; including 9 simulations of the PBL with different values of $\overline{\left(w^{\prime} \theta_{0}^{\prime}\right.}=0.01,0.05$ and $\left.0.24 \mathrm{~K} \mathrm{~m} \mathrm{~s}^{-1}\right)$ and $U_{g}\left(=5,10,15 \mathrm{~m} \mathrm{~s}^{-1}\right)$, free convection $\left(\overline{w^{\prime} \theta_{0}^{\prime}}=0.01\right.$ and $0.24 \mathrm{~K} \mathrm{~m} \mathrm{~s}^{-1}-1, U_{g}=$ $\left.0.0 \mathrm{~ms}^{-1}\right)$, and the purely shear-driven boundary layer $\overline{\left(w^{\prime} \theta_{0}^{\prime}\right.}=0.0 \mathrm{~K} \mathrm{~m} \mathrm{~s}^{-1}, U_{g}=$ $10 \mathrm{~m} \mathrm{~s}^{-1}$ ). We list the parameters of each simulation in Table I.

In order to compare the results from the one-dimensional PBL models with the LES data, the LES model was integrated first until satisfying $t_{0}>6 \tau^{*}$, where the large-eddy turnover time $\tau^{*}$ is determined by $h / w_{*}$ (or $h / u_{*}$ in the purely sheardriven boundary layer), since it is required to reach a statistically quasi-steady state of the dynamic flow field (Moeng and Sullivan, 1994). In accordance with this we integrated the LES model until $t_{0}=6000 \mathrm{~s}$ for $\overline{w^{\prime} \theta_{0}^{\prime}}=0.05$ and $0.24 \mathrm{~K} \mathrm{~m} \mathrm{~s}^{-1}, t_{0}$ 
$=9000 \mathrm{~s}$ for $\overline{w^{\prime} \theta_{0}^{\prime}}=0.01 \mathrm{~K} \mathrm{~m} \mathrm{~s}^{-1}$, and $t_{0}=90000 \mathrm{~s}$ for the purely shear-driven boundary layer. We regarded $t_{0}$ as the starting time of the simulation for both the LES and PBL models, and carried out the integration for another $6000 \mathrm{~s}$. For the initial conditions of the PBL models, such as the profiles of potential temperature and velocity, we used the LES data at $t=t_{0}$. An analysis of LES data, used in Section 3, was also carried out using the data at the final time step $\left(t=t_{0}+6000 \mathrm{~s}\right)$. The horizontal mean profiles from LES were obtained by averaging over a $600 \mathrm{~s}$ period.

\section{Modification of the TM Model}

\subsection{INCORPORATION OF ENTRAINMENT INTO THE HEAT FLUX PROFILE}

If we define $h$ as the height of the minimum heat flux in the conventional way, the heat flux given by (1) and (2) disappears at $z=h$. It is equivalent to the heat flux in the nonpenetrative convective boundary layer with a solid lid. In this case, the heat flux profile requires an additional contribution from the entrainment at the top of the PBL.

Sorbjan (1996) compared the heat fluxes between the penetrative and nonpenetrative convective boundary layer, and found that the difference between the heat fluxes decreases continuously with the distance from the inversion layer. Its monotonic decrease, regardless of the temperature gradient, suggests that the downward heat transfer from the inversion layer must be also parameterized by non-local mixing.

Therefore, we propose the addition of the contribution of the heat flux owing to the entrainment at the top of the PBL into the original heat flux profile in the TM model in the following way:

$$
-\overline{w^{\prime} \theta^{\prime}}=K_{h}\left(\frac{\partial \theta}{\partial z}-\gamma_{h}\right)-\overline{w^{\prime} \theta_{h}^{\prime}}\left(\frac{z}{h}\right)^{n} .
$$

Here we obtained the empirical constant $n$ as $n=3$ based on the comparison between the model results and LES data, but the results were found to be highly insensitive to the choice of $n$. For example, the simulations with substantially different values of $n$, such as $n=1$ or 5 , also give similar results, because the contribution of the new term is negligible except near the top of the PBL. The Kprofile used in (16) is the same as in the TM model. The parameterization of $\overline{w^{\prime} \theta_{h}^{\prime}}$ will be discussed in the next section.

To complete the heat flux profile we also need to parameterize the heat flux above the top of the PBL $(z>h)$. The inversion layer is stably stratified, and thus we can assume that the heat transfer occurs only by local mixing. On the other hand, from the analysis of LES data, we found that the TKE level in the inversion layer is much larger than that expected from the local wind shear production, which 
renders the Louis scheme (1979) irrelevant here. So we can conjecture that it is controlled by the TKE transfer from the impinging thermals.

According to Deardorff et al. (1980), the thickness of the entrainment zone, $\delta$, can be estimated as

$$
\delta / h=d_{1}+d_{2} R i_{*}^{-1},
$$

where $R i_{*}\left(=\left(g / T_{0}\right) h \Delta \theta / w_{*}^{2}\right)$ is the convective Richardson number, and $d_{1}$ and $d_{2}$ are constants. In the presence of shear, we can generalize $w_{*}$ in $R i_{*}$ to $w_{m}(=$ $\left(w_{*}^{3}+B u_{*}^{3}\right)^{1 / 3}$ ), which is the velocity scale for the entrainment (see the next section for its meaning).

Therefore, we propose to represent the heat flux at $z>h$ as

$$
-\overline{w^{\prime} \theta^{\prime}}=K_{h} \frac{\partial \theta}{\partial z}
$$

with

$$
K_{h}=\frac{-\overline{w^{\prime} \theta_{h}^{\prime}}}{(\partial \theta / \partial z)_{h}} \exp \left[-\frac{(z-h)^{2}}{\delta^{2}}\right] .
$$

In (19) we determine the magnitude of $K_{h}$ so as to match with the heat flux by entrainment at $z=h$. We could obtain the empirical constants as $d_{1}=0.02$ and $d_{2}=0.05$ from the comparison of the model results and the LES data. It is also important to note that the non-local mixing is still present above the inversion layer in the TM model.

Finally, we would like to mention that Lock et al. (2000) and Holtslag and Moeng (1991) attempted to incorporate the effects of entrainment by modifying the K-profile itself. For example, Lock et al. (2000) suggested a modification of the K-profile that corresponds to

$$
K_{h}=P r^{-1} k w_{s} z\left(1-R \frac{z}{h}\right)^{2},
$$

where $R$ is determined by matching the value obtained from (20) to $-\overline{w^{\prime} \theta_{h}^{\prime}}$ (or $-\overline{u^{\prime} w_{h}^{\prime}}$ for the case of $K_{m}$ ). However, not only it is very complicated to relate $R$ to $-\overline{w^{\prime} \theta_{h}^{\prime}}$ (or $-\overline{u^{\prime} w_{h}^{\prime}}$ ) in $(20)$, but also it does not appear natural that $R$ must be different for $K_{m}$ and $K_{h}$.

\subsection{DeterminAtion OF THE ENTRAinMENT RATE}

The new model represents the entrainment rate explicitly in the heat flux profile, so it requires the information about its value.

There have been numerous investigations to predict the entrainment rate or the heat flux at the inversion layer (Ball, 1960; Stull, 1976; Deardorff, 1979; 
Driedonks, 1982; van Zanten et al., 1999; Lock, 1998; Moeng and Sullivan, 1994; Zeman and Tennekes, 1977).

For example, the heat flux at the inversion layer $\overline{w^{\prime} \theta_{h}^{\prime}}$ in the free convection is usually estimated by

$$
\overline{\overline{w^{\prime} \theta_{h}^{\prime}}}=-A_{R}
$$

or

$$
\overline{w^{\prime} \theta_{h}^{\prime}}=-A w_{*}^{3} / h
$$

and the appropriate value for $A_{R}\left(=\left(g / T_{0}\right) A\right)$ is suggested to be in the range between 0.1 and 0.3 (Ball, 1960).

Meanwhile, in the presence of shear, Moeng and Sullivan (1994) and Driedonks (1982) extended the above formula to

$$
\overline{w^{\prime} \theta_{h}^{\prime}}=-A w_{m}^{3} / h
$$

where

$$
w_{m}^{3}=w_{*}^{3}+B u_{*}^{3}
$$

with the suggested value $B=5$ (Moeng and Sullivan, 1994) or $B=25$ (Driedonks, 1982). Note that the velocity scale $w_{s}$ cannot be applied here, because the efficiency of entrainment is different between shear-driven and convective turbulence.

We evaluated the above formula ((23) and (24)) using the LES data (Figure 4). To obtain Figure 4, we assumed the value of $h$ as the height of the minimum heat flux $\overline{w^{\prime} \theta_{h}^{\prime}}$ in the heat flux profile. We found that the relation (23) is satisfied reasonably with $B=5$, consistent with Moeng and Sullivan (1994). We also found the optimal value for $A$ as $A \simeq 4.5$ (or $A_{R} \simeq 0.15$ ).

\subsection{VERTICAL VARIATION OF THE VERTICAL VELOCITY SCALE AND THE PRANTDL NUMBER}

One important implication of the TM model is that the velocity scale $w_{s}$, which is determined at the top of the surface layer $(z=0.1 \mathrm{~h})$, should remain invariant throughout the boundary layer. Meanwhile, it is well known that the turbulence production by shear is limited to the region close to the surface, while that by buoyancy extends through to the whole boundary-layer height (Moeng and Sullivan, 1994; Stull, 1988; Lenschow et al., 1980). The turbulence in the convective boundary layer is increasingly dominated by convection with increasing $z$ and thus the relative contribution of the convective velocity scale $w_{*}$ in $w_{s 0}$ should increase with $z$. It is also noted that the K-profile in the TM model, determined by (2) and 
(9), does not obey the free convection limit, $K_{h} \propto z^{4 / 3}$ for $z \ll h$ (Panofsky and Dutton, 1984), as mentioned earlier.

Therefore, we suggest a modified form of the velocity scale $w_{s}$ as,

$$
w_{s}=\left(u_{*}^{3}+7 k w_{*}^{3} z / h\right)^{1 / 3} .
$$

The velocity scale given by (25) coincides with (3) at the top of the surface layer, that is, $w_{s}=w_{s 0}$ at $z=\varepsilon h$, but the contribution of $w_{*}$ increases with $z$. In this case the K-profile approaches the eddy diffusivity in the free convection, when $7 k w_{*}^{3} z / h \gg u_{*}^{3}$; that is,

$$
K_{h}=C_{k} w_{*} h\left(\frac{z}{h}\right)^{4 / 3}\left(1-\frac{z}{h}\right)^{2},
$$

where $C_{k}=\operatorname{Pr}^{-1} k(7 k)^{1 / 3} \simeq 1$.

Likewise, the TM model also assumes that the Prandtl number, which is determined by the stability at the top of the surface layer $(z=\varepsilon h)$, remains invariant with height. Nevertheless, the stability of the convective boundary layer itself changes from unstable near the surface layer to stable at the upper boundary. Accordingly, the Prandtl number is also expected to vary within the PBL.

Therefore, we suggest that the Prandtl number also varies within the boundary layer according to the local stability, and has a presumed profile shape, similar to the case of eddy diffusivity. The profile of the Prandtl number is proposed to vary as

$$
\operatorname{Pr}=1+\left(P r_{0}-1\right) \exp \left[-\alpha(z-\varepsilon h)^{2} / h^{2}\right],
$$

where $P r_{0}$ is the Prandtl number at the top of the surface layer given by (15) and $\alpha$ is an empirical constant. The profile given by (27) implies that the Prandtl number, which has the same value as in the TM model at $z=\varepsilon h$, increases continuously, approaching a typical value for weak stratification near the top of the boundary layer, such as $P r \simeq 1$ (Deardorff, 1980; Wittich and Roth, 1984). The appropriate value of $\alpha$ was found to be $\alpha \simeq 3$ by matching the heat flux profiles from the new PBL model with LES data. Note that the Equation (15), to determine the Prandtl number in the surface layer, also increases from 0.26 in free convection to 1.0 in the neutrally stable surface layer with $b_{0}=0$.

\subsection{DETERMINATION OF THE COUNTERGRADIENT TERM}

In the TM model the countergradient term is estimated by (10) with $b_{0}=6.5$. However, in the present model the velocity scale is no longer constant, but varies with height. Accordingly, we need to modify the relation (10) to

$$
\gamma_{h}=b \frac{\overline{w^{\prime} \theta_{0}^{\prime}}}{w_{s}(h / 2) h} \text {. }
$$




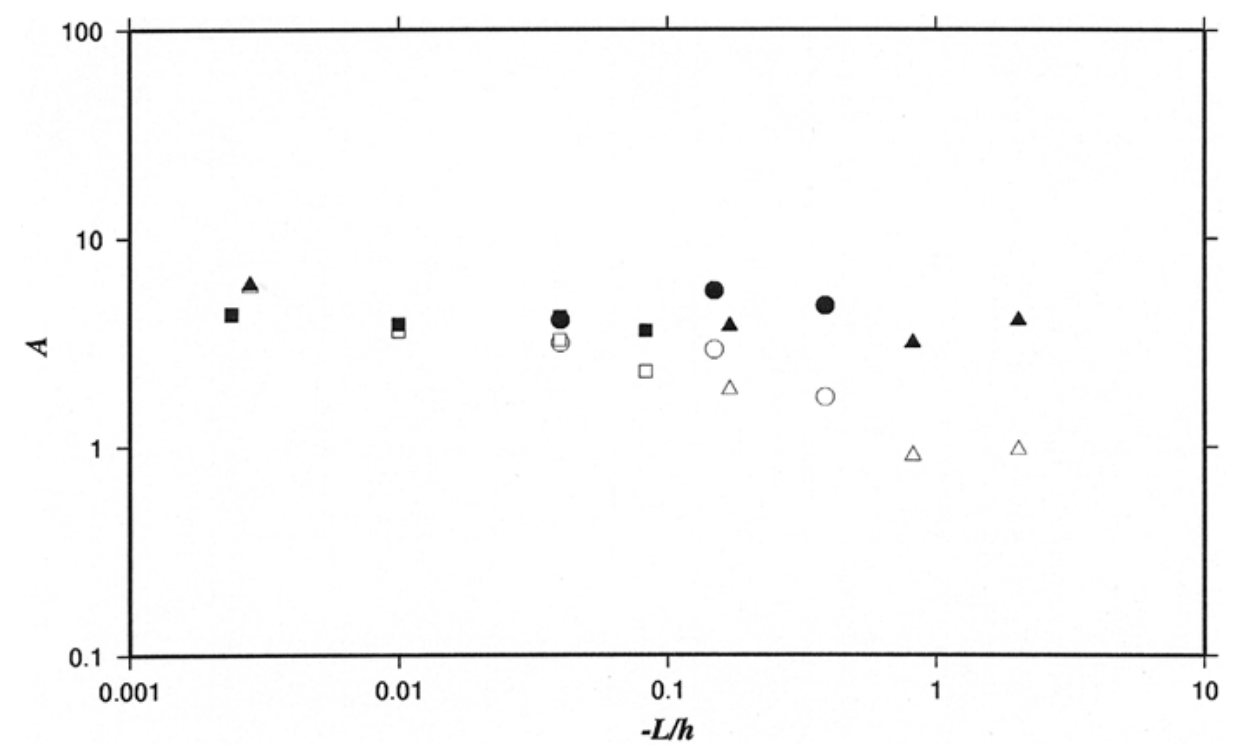

Figure 1. Variation of the entrainment rate scaled by $w_{*}^{3}+B u_{*}^{3}$ with $-L / h ; \triangle: \overline{w^{\prime} \theta_{0}^{\prime}}=0.01 \mathrm{~m} \mathrm{~s}^{-1} \mathrm{~K}$, $\bigcirc: \overline{w^{\prime} \theta_{0}^{\prime}}=0.05 \mathrm{~m} \mathrm{~s}^{-1} \mathrm{~K}, \square: \overline{w^{\prime} \theta_{0}^{\prime}}=0.24 \mathrm{~m} \mathrm{~s}^{-1} \mathrm{~K}$ (open symbols: $B=25$, closed symbols: $B=5$ ). Here we do not include the case $S$, in which the contribution of the subgrid scale heat flux becomes larger than $20 \%$.

Figure 2 compares the evaluated values of $b_{0}$ in (10) for the case of the TM model and of $b$ in the new model, and their variations with $-L / h$. Here the values of $\gamma_{h}$ are evaluated from the heat flux profiles from LES at the height $z^{*}$ where $\partial \theta / \partial z=$ 0 , using the relation (1) or (16). Similar values are obtained in both cases, although they are slightly larger in the new model. The magnitude of $b_{0}$ is also in agreement with the value suggested by in the TM model as $b_{0}=6.5$. Although $b$ is slightly larger than $b_{0}$, we still used $b=6.5$ to obtain the heat flux profiles in Figure 2, since its effect is insignificant. In this way, we can examine the effects of the modified K-profile more clearly.

Considering the above evaluation, it is more consistent to use the value of $w_{s}$ at $z=z^{*}$ rather than that at $z=h / 2$. However, we use the value at $z=h / 2$, because it is much simpler to execute in the model. For practical purposes this makes hardly any difference, since $w_{s}$ varies very slowly in the middle of the PBL.

\subsection{Determination of the PBL height}

Contrary to the TM model, the growth of the boundary-layer height, $h$, is controlled basically by the vertical mixing process, such as (16), in the new PBL model. Nonetheless, information on the PBL height is still required to determine the profile of $K_{h}$ and the velocity scale $w_{s}$. For this purpose, however, it suffices to estimate $h$ diagnostically from the profiles of mean potential temperature. 


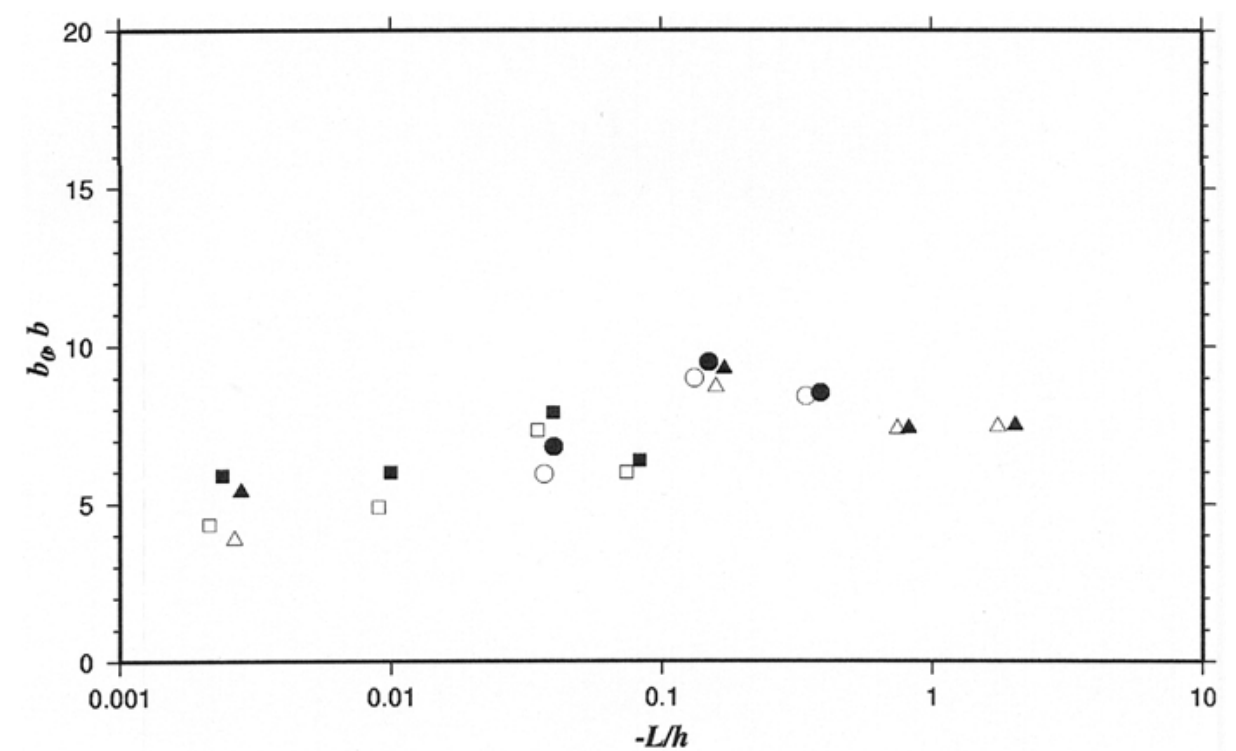

Figure 2. Variation of the coefficient of the countergradient term with $-L / h ; \diamond: \overline{w^{\prime} \theta_{0}^{\prime}}=0.0 \mathrm{~m} \mathrm{~s}^{-1} \mathrm{~K}$, $\triangle: \overline{w^{\prime} \theta_{0}^{\prime}}=0.01 \mathrm{~m} \mathrm{~s}^{-1} \mathrm{~K}, \bigcirc: \overline{w^{\prime} \theta_{0}^{\prime}}=0.05 \mathrm{~m} \mathrm{~s}^{-1} \mathrm{~K}, \square: \overline{w^{\prime} \theta_{0}^{\prime}}=0.24 \mathrm{~m} \mathrm{~s}^{-1} \mathrm{~K}$ (open symbols: TM model $\left(b_{0}\right)$, closed symbols: New model $(b)$ ). In the TM model, $h$ is determined by the height at which the magnitude of the heat flux decreases to one tenth of that of the minimum heat flux at the inversion layer.

For example, Ayotte et al. (1996) suggested a method to estimate $h$ from the potential temperature profile as

$$
\theta(h) \geq \frac{1}{h} \int_{0}^{h} \theta(z) d z+\theta_{M 0} .
$$

As a simpler method, we define $h$ according to the following definition

$$
\theta(h)=\theta(h / 2)+\theta_{M} .
$$

Although $\theta_{M 0}$ is assumed constant in Ayotte et al. (1996), we found from the comparison with the LES data that the value of $\theta_{M}$ is given by

$$
\theta_{M}=b_{\theta} \frac{\overline{w^{\prime} \theta_{h}^{\prime}}}{w_{s}(h / 2)}
$$

The relation (31) implies that the temperature gradient in the upper boundary layer depends on how much warmer air is entrained across the inversion layer and how fast it is mixed within the boundary layer by the turbulence with the velocity scale $w_{s}$. 


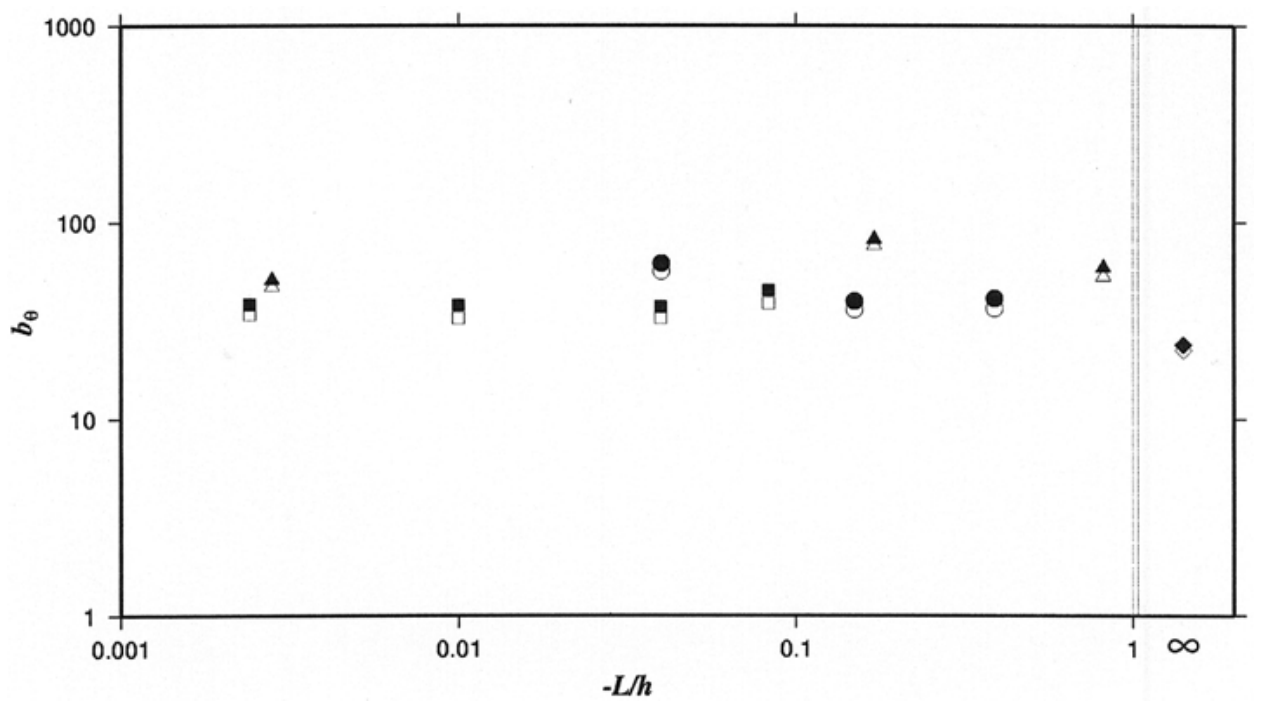

Figure 3. Variation of the potential temperature difference scaled by $\overline{w^{\prime} \theta_{h}^{\prime}} / w_{s}(h / 2)$ with $-L / h ; \diamond$ : $\overline{w^{\prime} \theta_{0}^{\prime}}=0.0 \mathrm{~m} \mathrm{~s}^{-1} \mathrm{~K}, \triangle: \overline{w^{\prime} \theta_{0}^{\prime}}=0.01 \mathrm{~m} \mathrm{~s}^{-1} \mathrm{~K}, \bigcirc: \overline{w^{\prime} \theta_{0}^{\prime}}=0.05 \mathrm{~m} \mathrm{~s}^{-1} \mathrm{~K}, \square: \overline{w^{\prime} \theta_{0}^{\prime}}=0.24 \mathrm{~m} \mathrm{~s}^{-1} \mathrm{~K}$ (open symbols: $\theta_{M 0}=\theta(h)-\int_{0}^{h} \theta(z) d z / h$, closed symbols: $\left.\theta_{M}=\theta(h)-\theta(h / 2)\right)$.

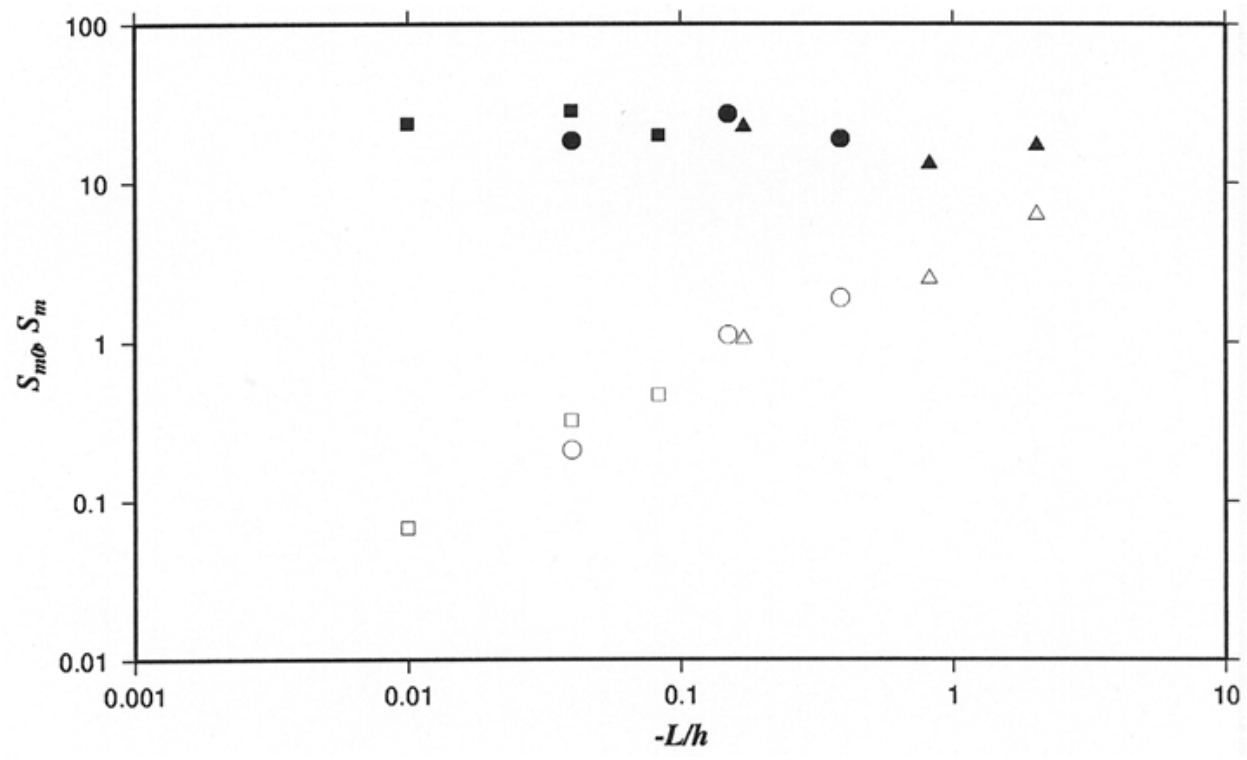

Figure 4. Variation of the coefficient of the countergradient term for momentum flux with $-L / h ; \diamond$ : $\overline{w^{\prime} \theta_{0}^{\prime}}=0.0 \mathrm{~m} \mathrm{~s}^{-1} \mathrm{~K}, \triangle: \overline{w^{\prime} \theta_{0}^{\prime}}=0.01 \mathrm{~m} \mathrm{~s}^{-1} \mathrm{~K}, \bigcirc: \overline{w^{\prime} \theta_{0}^{\prime}}=0.05 \mathrm{~m} \mathrm{~s}^{-1} \mathrm{~K}, \square: \overline{w^{\prime} \theta_{0}^{\prime}}=0.24 \mathrm{~m} \mathrm{~s}^{-1} \mathrm{~K}$ (open symbols: $S_{m 0}$ (Frech and Mahrt, 1995), closed symbols: $S_{m}$ (Brown and Grant, 1997)). 
Figure 3 shows the values of $\theta_{M 0}$ and $\theta_{M}$, scaled by (31), which are obtained from (29) and (30) using the mean potential profiles from LES. Both results support the scaling given by (31). Based on the results shown in Figure 3, we suggest the empirical constant as $b_{\theta} \simeq 46$. Because the potential temperature increases rapidly at the inversion layer, the calculated value of $h$ is insensitive to the value of $b_{\theta}$.

It is important, however, to note that there exists an important conceptual difference in the determination of $h$ here and from (14) in the TM model. In the TM model, it is a dynamical process to predict the growth of $h$ by (11), in which the boundary layer is assumed to grow to satisfy the local stability criterion at the inversion layer. On the other hand, in the new model it is merely to locate $h$, once the boundary-layer growth is accomplished by the heat transfer according to (16). Moreover, $h$ represents the height of the minimum heat flux in the new model unlike the TM model.

\subsection{DETERMINATION OF THE NON-LOCAL MIXING FOR MOMENTUM}

We include the non-local momentum mixing in the new model, following the suggestion by Frech and Mahrt (1995) and Brown and Grant (1997).

Frech and Mahrt (1995) proposed the parameterization of the non-local flux of momentum as

$$
\gamma_{m}=-S_{m 0} \frac{u_{*}^{2}}{w_{s 0} h}\left(\frac{w_{*}}{u_{*}}\right)^{m} \frac{\Delta u}{\left[(\Delta u)^{2}+(\Delta v)^{2}\right]^{1 / 2}},
$$

with $m=3$, where $\Delta u$ and $\Delta v$ are the changes in $u$ and $v$ between the top of the surface layer and the model level just below $h$, and $S_{m 0}$ is a proportional coefficient. Since $\Delta u \gg \Delta v$ in the present simulations, (32) can become

$$
\gamma_{m}=-S_{m 0} \frac{u_{*}^{2}}{w_{s} h}\left(\frac{w_{*}}{u_{*}}\right)^{m} .
$$

Meanwhile, Brown and Grant (1997) suggest that $u_{*}$ is better replaced by $w_{s}$ in the $\left(w_{*} / u_{*}\right)^{m}$ factor, i.e.,

$$
\gamma_{m}=-S_{m} \frac{u_{*}^{2}}{w_{s} h}\left(\frac{w_{*}}{w_{s}}\right)^{m} .
$$

We evaluated the amount of non-local mixing of momentum from the LES data. Because $\partial u / \partial z$ becomes zero at two different heights, contrary to the case of $\partial \theta / \partial z$, we calculated $\gamma_{m}$ by averaging the values obtained over the whole boundary layer, that is,

$$
\gamma_{m}=\frac{1}{z_{t}-z_{b}} \int_{z_{b}}^{z_{t}} \frac{-\overline{u^{\prime} w^{\prime}}-K_{m} \partial u / \partial z}{K_{m}} d z .
$$


Here the integration range was given by $z_{b}=0.1 h$ and $z_{t}=0.9 h$.

Analysis of the LES data supports the formula (34) by Brown and Grant (1997). For the evaluation of the right hand side of (33) and (34) we used the value of $w_{s}$ at $z=h / 2$. We also found that the values of $S_{m}$ are not sensitive to the value of $m$, since $w_{*} / w_{s} \simeq 1$ in most cases. We employ the parameterization of (34) with $S_{m} \simeq 15.9$ in the model.

As in the case of heat flux profile, we also included the effects of the entrainment at the inversion layer in the momentum flux profile as

$$
-\overline{u^{\prime} w^{\prime}}=K_{m}\left(\frac{\partial u}{\partial z}-\gamma_{m}\right)-\overline{u^{\prime} w_{h}^{\prime}}\left(\frac{z}{h}\right)^{n}
$$

for $z<h$, where the same empirical constant $n=3$ is used as in the heat flux profile (16). The parameterization of $\left(\overline{u^{\prime} w^{\prime}}\right)_{h}$ in (36) will be discussed in the next section.

For $z>h$, we need the momentum flux to decrease exponentially with $z$ over the distance $\delta$, similar to (18) and (19); that is

$$
-\overline{u^{\prime} w^{\prime}}=K_{m} \frac{\partial u}{\partial z}
$$

with

$$
K_{m}=\frac{-\overline{u^{\prime} w_{h}^{\prime}}}{(\partial u / \partial z)_{h}} \exp \left[-\frac{(z-h)^{2}}{\delta^{2}}\right] \text {. }
$$

\subsection{DETERMINATION OF MOMENTUM FLUX AT THE INVERSION LAYER}

Because both the heat and momentum fluxes at the inversion layer are generated by the same mechanism, i.e., entrainment, we expect that they should be closely related. Therefore, we suggest that

$$
\frac{\left(\overline{w^{\prime} \theta^{\prime}}\right)_{h}}{\left(\overline{u^{\prime} w^{\prime}}\right)_{h}}=C_{h} \frac{\Delta \theta_{h}}{\Delta u_{h}}
$$

where $\Delta \theta_{h}$ and $\Delta u_{h}$ are the changes of potential temperature and velocity across the inversion layer; for example, $\Delta \theta_{h}=\theta(h+\delta)-\theta(h)$ and $\Delta u_{h}=u(h+\delta)-u(h)$. The LES data also support the above relation with $C_{h} \simeq 0.5$ (Figure 5). Therefore, the relation (40) will be used in the model to calculate $\left(\overline{u^{\prime} w^{\prime}}\right)_{h}$, once $\left(\overline{w^{\prime} \theta^{\prime}}\right)_{h}$ is obtained from (23). 


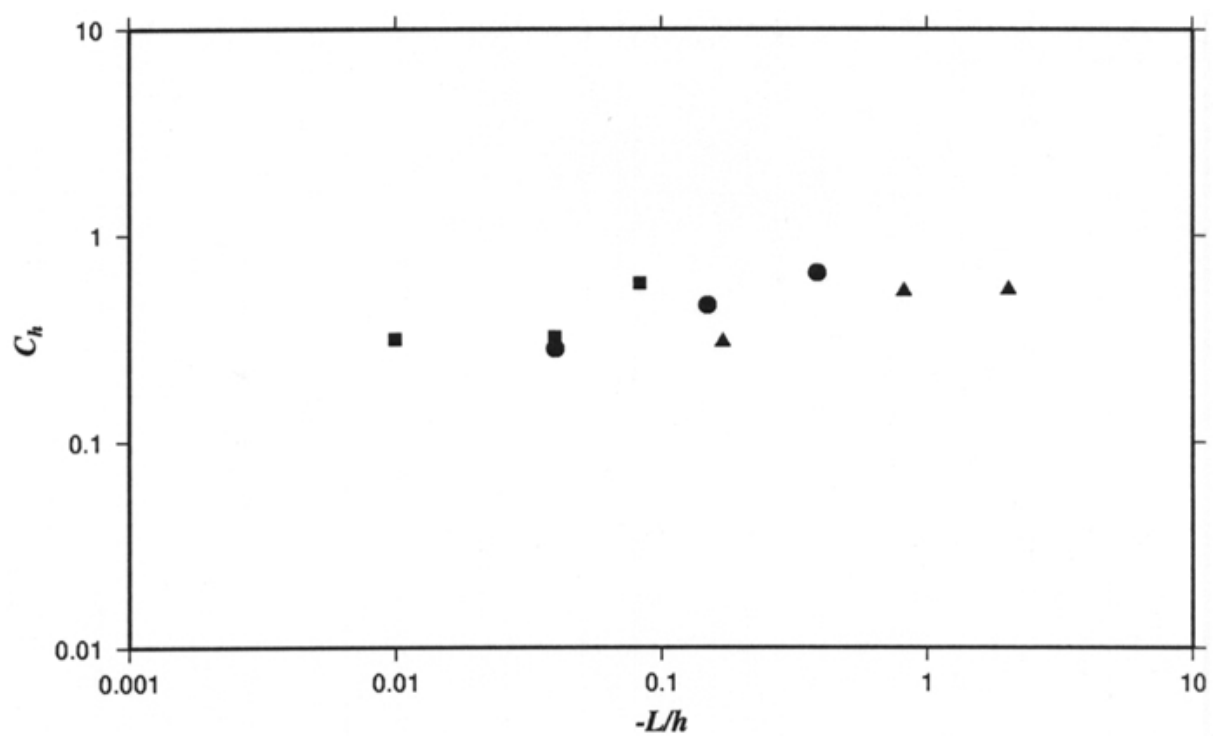

Figure 5. Relation between the heat flux and momentum flux at the inversion layer given by (40); $\boldsymbol{\Delta}$ $\overline{w^{\prime} \theta_{0}^{\prime}}=0.01 \mathrm{~m} \mathrm{~s}^{-1} \mathrm{~K}, \boldsymbol{\bullet}: \overline{w^{\prime} \theta_{0}^{\prime}}=0.05 \mathrm{~m} \mathrm{~s}^{-1} \mathrm{~K}, \mathbf{\square}: \overline{w^{\prime} \theta_{0}^{\prime}}=0.24 \mathrm{~m} \mathrm{~s}^{-1} \mathrm{~K}$.

\section{Comparison of the PBL Model Results with the LES Data}

\subsection{EXPERIMENTS}

We developed one-dimensional codes of both the new PBL model and the TM model, and examined the performance of the PBL models in comparison with the LES data. The basic features of the new PBL model are listed in comparison with the TM model in Table II. Hereafter we call the new PBL model and the TM model as NEW and TM. The vertical grid size of the PBL models was set the same as that of the LES model. Monin-Obukhov similarity is assumed between the surface and the first computational grid in the same way as in the LES model. We did not apply the Louis scheme (1979) in the free atmosphere, however, unlike the case of the actual implementation (Hong and Pan, 1996), because we want to concentrate on the performance of the PBL models exclusively.

Further, we investigated how the PBL model is affected by each of the three modifications made; that is, the explicit representation of the entrainment rate in the heat and momentum flux profiles, the inclusion of non-local momentum mixing, and the vertically varying Prandtl number and velocity scale. For this purpose, we modified the new PBL model in two ways. The first modified model has constant $P r_{0}$ and $w_{s 0}$ instead of the vertically varying $\operatorname{Pr}$ and $w_{s}$, which we will call NEW0. The second modified model (NEW1) is the same NEW0 except that the non-local mixing of momentum is neglected. Further, the model NEW1 and the TM model 
TABLE II

Comparison of the TM model and the new model.

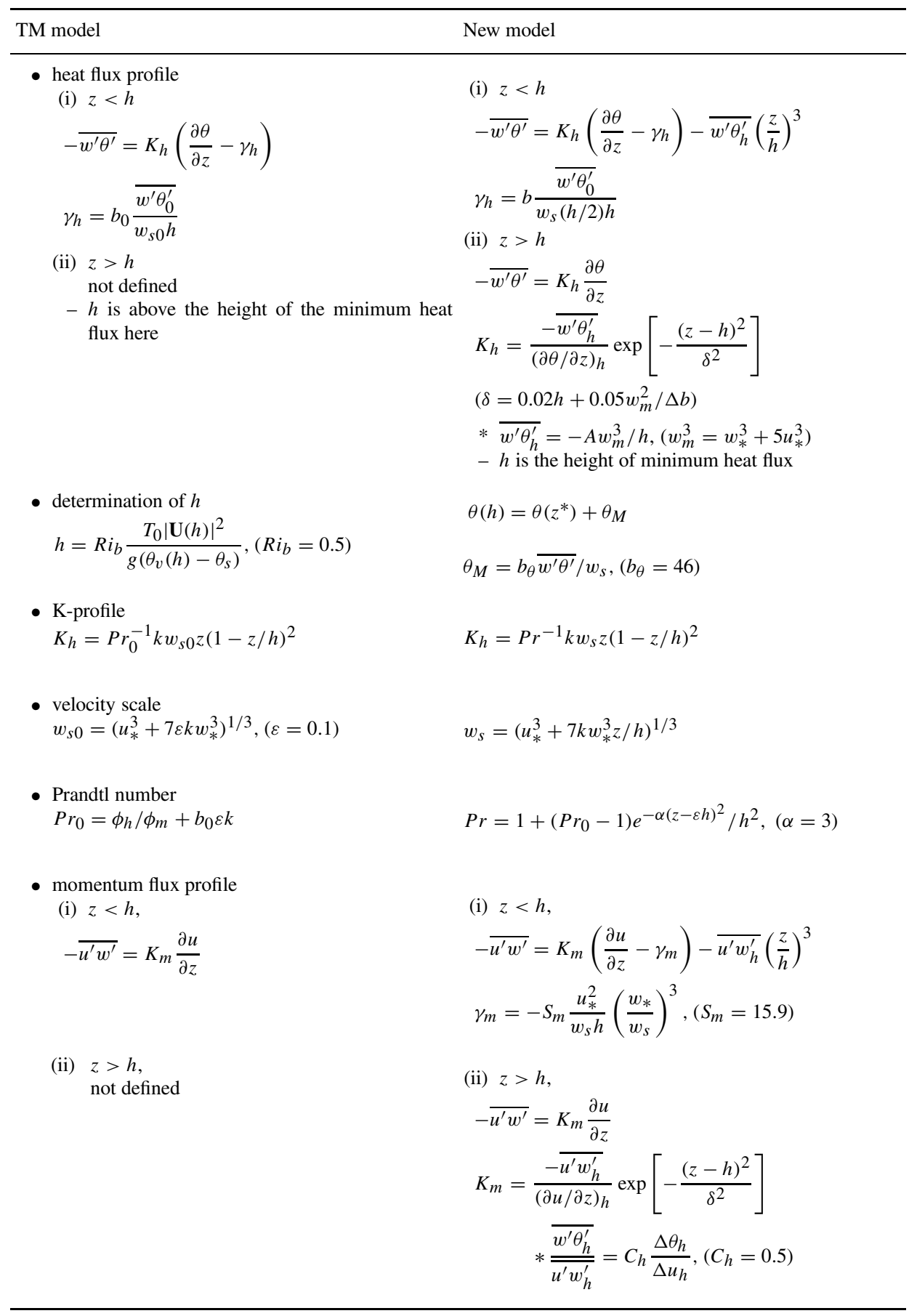


are different only in the explicit representation of the entrainment rate in the heat and momentum flux profiles.

\subsection{COMPARISON OF PROFILES}

Figures 6,7 and 8 compare the profiles of potential temperature, heat flux, and mean velocity at $t=t_{0}+6000 \mathrm{~s}$ from LES, the TM model, and the new PBL model. Initial profiles at $t=t_{0}$ are also shown. Profiles are shown for three typical cases; free convection $\left(\mathrm{C} 0, \overline{w^{\prime} \theta_{0}^{\prime}}=0.24 \mathrm{~K} \mathrm{~m} \mathrm{~s}^{-1}, U_{g}=0 \mathrm{~m} \mathrm{~s}^{-1}\right)$, the PBL affected by strong shear $\left(\mathrm{A} 3, \overline{w^{\prime} \theta_{0}^{\prime}}=0.01 \mathrm{~K} \mathrm{~m} \mathrm{~s}^{-1}, U_{g}=15 \mathrm{~m} \mathrm{~s}^{-1}\right)$, and an intermediate one (B2, $\overline{w^{\prime} \theta_{0}^{\prime}}=0.05 \mathrm{~K} \mathrm{~m} \mathrm{~s}^{-1}, U_{g}=10 \mathrm{~m} \mathrm{~s}^{-1}$ ).

The profiles of potential temperature show that the PBL grows too fast in the PBL with strong shear (A3) and too slow in the free convection case (C0) in the TM model (Figure 6). Besides, it is found that the potential temperature in the free convection case $(\mathrm{C} 0)$ from the TM model is not sufficiently mixed compared to the LES data, thus showing weak stable stratification throughout the PBL.

Moreover, a substantial disagreement between the LES data and the TM model results is observed in the heat flux profiles (Figure 7). The TM model seriously overestimates the negative heat flux at the inversion layer in the PBL with strong shear (A3), and it underestimates it in the free convection (C0). This clearly indicates that the TM model is not adequate to predict the heat flux. Besides the TM model produces too strong shear in the PBL, as expected from the absence of the non-local momentum mixing (Figure 8).

On the other hand, the new PBL model is able to reproduce profiles that are in much better agreement with the LES data, although that the mean velocity is somewhat weaker and the minimum heat flux in case A3 is slightly overestimated.

\subsection{Prediction of the PBL height}

We compared the PBL height from the PBL models and the LES data, as it is the most important element of the PBL prediction. For the consistent evaluation of the PBL height, we located the position of the minimum heat flux in the heat flux profile, such as Figure 7, instead of using the parameter $h$ used in the PBL models. Figure 9 compared the PBL heights from LES and PBL models under various conditions of the PBL (see Table 1). As expected from Figure 6, the TM model overestimates the PBL height as the shear becomes stronger in the PBL, and underestimates it as it approaches free convection. This result is in general agreement with the evaluation by Ayotte et al. (1996).

The TM model assumes that the PBL grows by adjusting $h$ at each time step so as to keep the bulk Richardson number $R i_{b}$, defined by (11), constant. The investigation of LES results reveals, however, that $R i_{b}$ does not remain constant at the inversion layer, but decreases with increasing shear (Figure 10). This means that the corresponding critical $R i_{b}$ should be smaller in the shear-dominated PBL, 
(a)

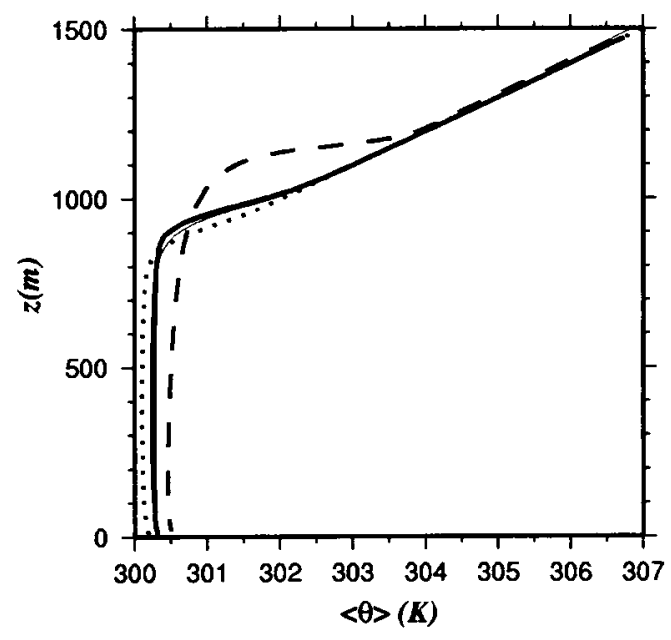

(b)

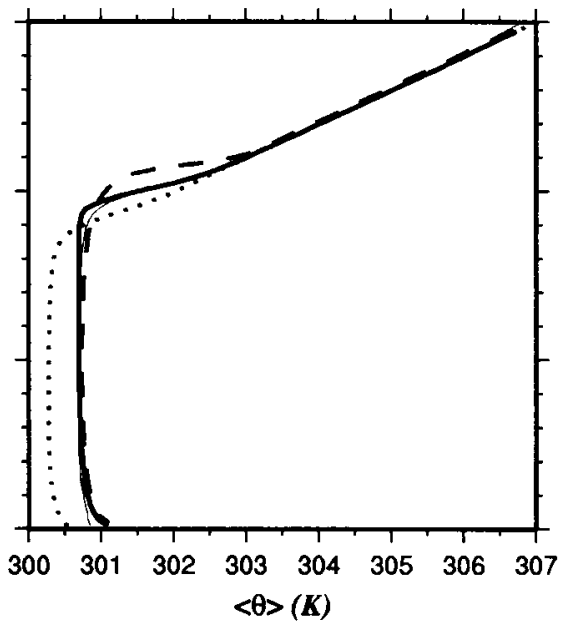

(c)

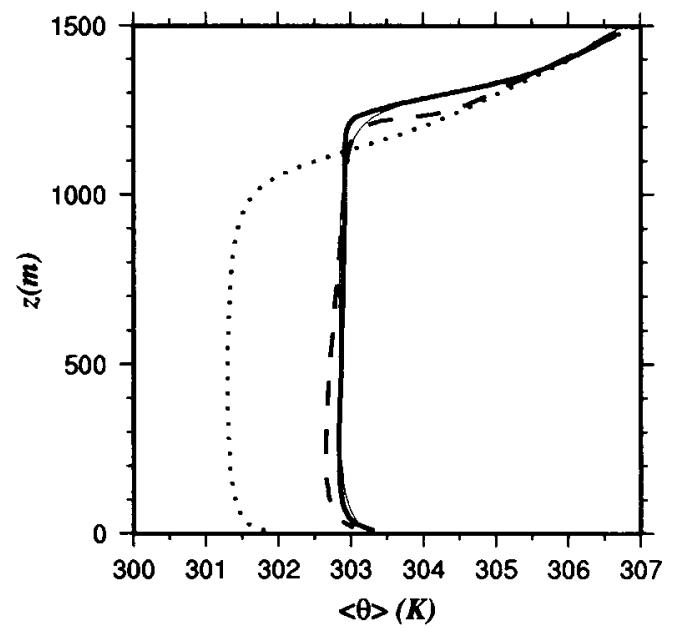

Figure 6. The profiles of potential temperature at $t=t_{0}+6000 \mathrm{~s}$ (Thin solid lines are LES results, thick solid lines are from the new PBL model, and dashed lines are from the TM model.) Initial profiles at $t=t_{0}$ are also shown (dotted lines); (a) $\mathrm{A} 3 \overline{\left(w^{\prime} \theta_{0}^{\prime}\right.}=0.01 \mathrm{~K} \mathrm{~m} \mathrm{~s}^{-1}, U_{g}=15 \mathrm{~m} \mathrm{~s}^{-1}$ ), (b) B2 $\left(\overline{w^{\prime} \theta_{0}^{\prime}}=0.05 \mathrm{~K} \mathrm{~m} \mathrm{~s}^{-1}, U_{g}=10 \mathrm{~m} \mathrm{~s}^{-1}\right)$, (c) $\mathrm{C} 0\left(\overline{w^{\prime} \theta_{0}^{\prime}}=0.24 \mathrm{~K} \mathrm{~m} \mathrm{~s}^{-1}, U_{g}=0 \mathrm{~m} \mathrm{~s}^{-1}\right)$.

and larger in the convection-dominated PBL. It is also worthwhile to mention that the prediction of the growth of the PBL based on local instability is found to be useful usually in the stable boundary layer (Mahrt et al., 1979; Wetzel, 1982; Vogelezang and Holtslag, 1996). Accordingly, we can expect from Figure 10 that the contribution of the second term in the right hand side of (14) is overestimated in the shear-dominated PBL and underestimated in the convection-dominated PBL, 
(a)

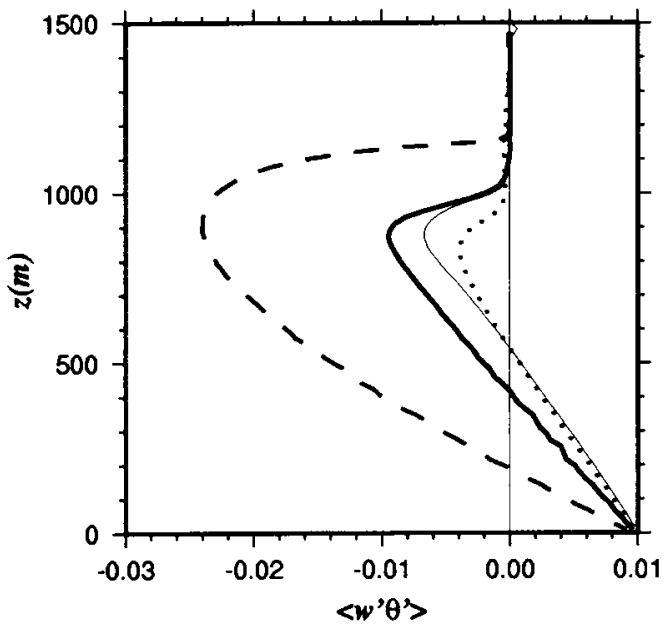

(b)

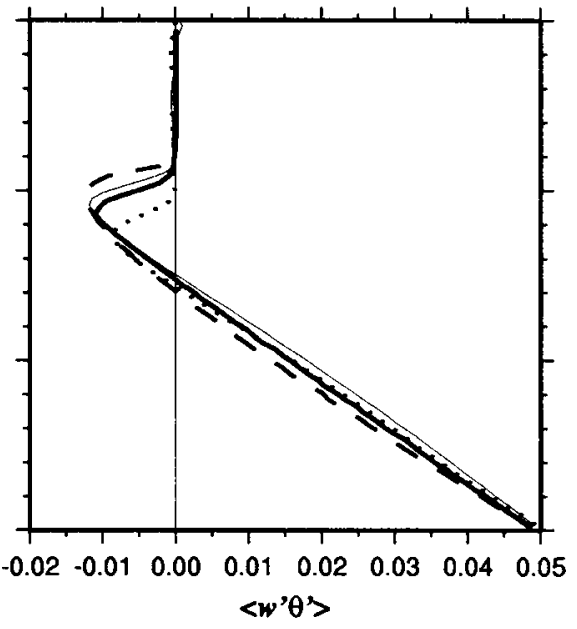

(c)

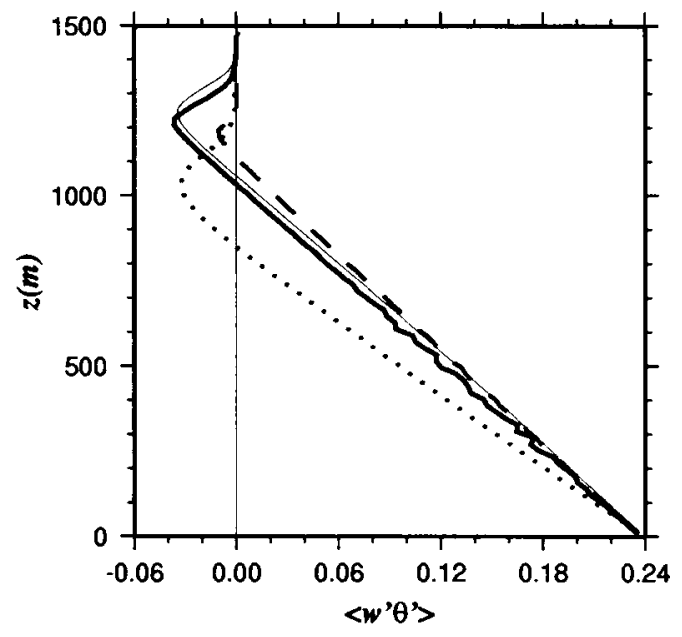

Figure 7. The profiles of heat flux (units of $\mathrm{K} \mathrm{m} \mathrm{s}^{-1}$ ) at $t=t_{0}+6000 \mathrm{~s}$ (Thin solid lines are LES results, thick solid lines are from the new PBL model, and dashed lines are from the TM model.) Initial profiles at $t=t_{0}$ are also shown (dotted lines); (a) A3, (b) B2, (c) C0.

which leads to the overestimation and underestimation of $h$, respectively, in the TM model, as shown in Figure 9.

This improper estimation of $h$ is also reflected in the heat flux profiles shown in Figure 7. In free convection, $h$ happens to be located too close to the top of the PBL, so that the value of heat flux at the inversion layer approaches zero according to (2). On the other hand, in the shear-dominated PBL, $h$ happens to be located higher than the top of the PBL, so that the combination of the strong stratification 
(a)

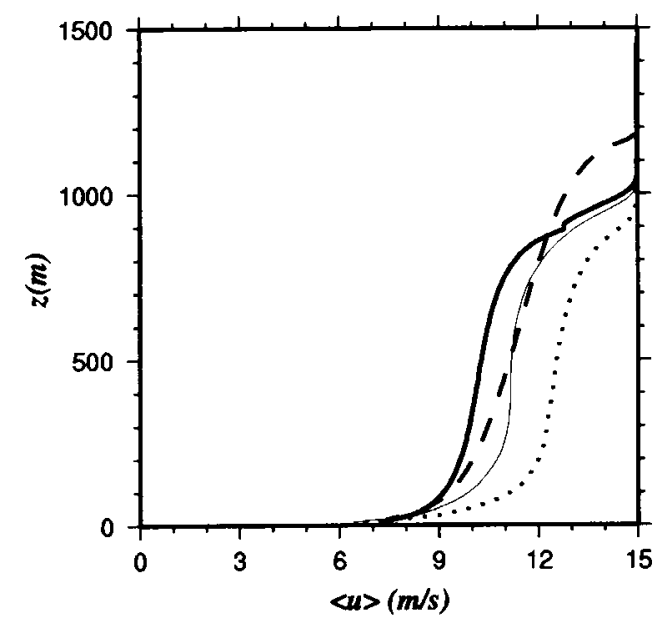

(b)

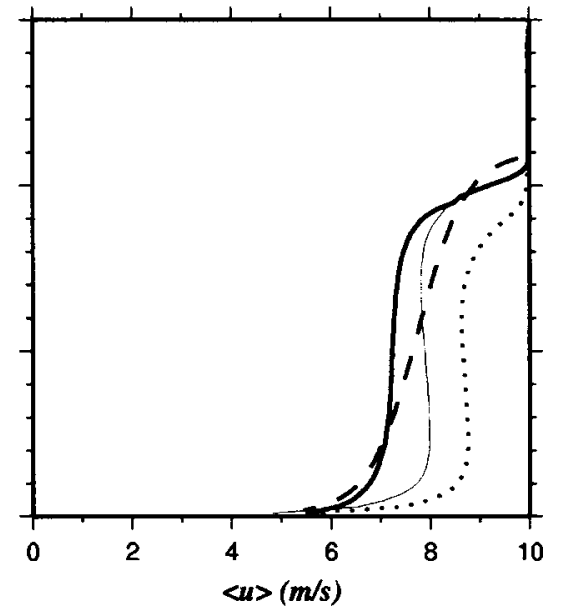

Figure 8 . The profiles of mean velocity in the $x$-direction at $t=t_{0}+6000 \mathrm{~s}$ (Thin solid lines are LES results, thick solid lines are from the new PBL model, and dashed lines are from the TM model.) Initial profiles at $t=t_{0}$ are also shown (dotted lines); (a) A3, (b) B2.

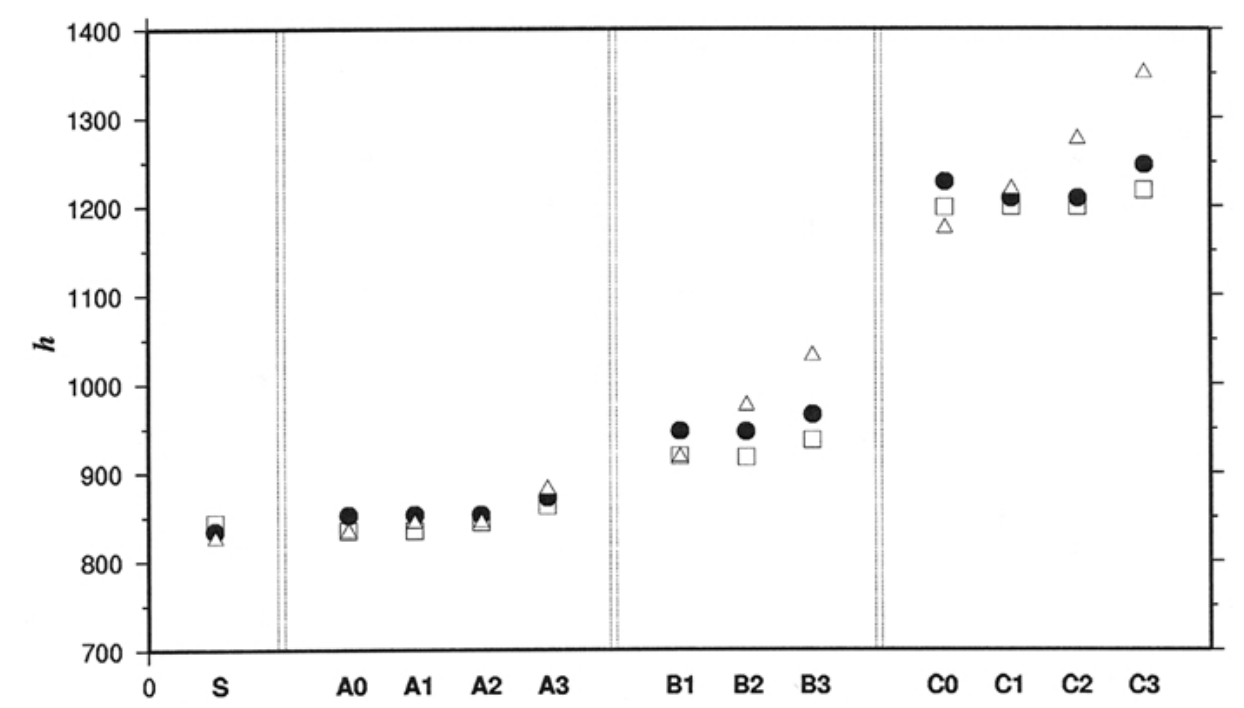

Figure 9. The comparison of the PBL height prediction at $t=t_{0}+6000 \mathrm{~s}$; $\bullet$ : LES, $\square$, new PBL model, $\triangle$ : TM model. See Table I for details of cases (S, A0, etc.).

at the inversion layer and the large value of $K_{h}$ there produces an excessively large negative heat flux at the inversion layer.

Much improvement is obtained from the new PBL model (Figure 9). The PBL heights from the new PBL model do not show any tendency depending on the characteristics of the PBL unlike the TM model, although the PBL heights tend to be slightly lower than the LES data. We also found that closer agreement with 


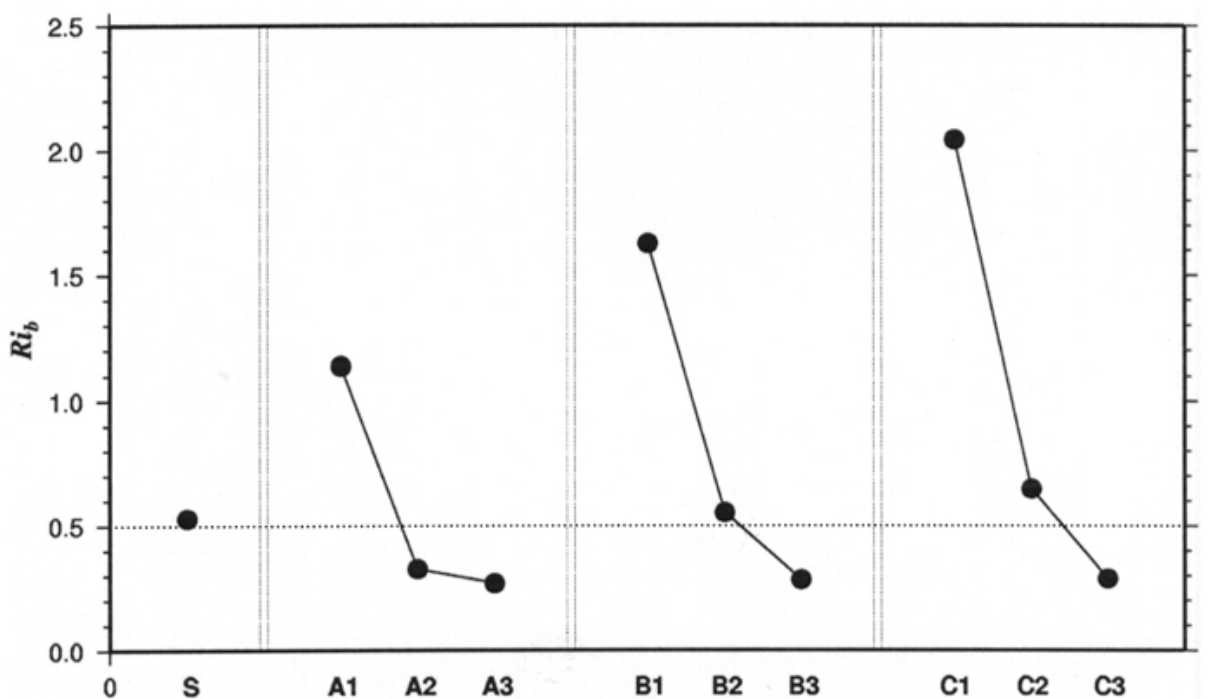

Figure 10. Variation of the bulk Richardson number at the inversion layer. Here $h$ is determined by the height at which the magnitude of the heat flux decreases to one tenth of that of the minimum heat flux at the inversion layer.

the LES data is obtained when the resolution of the PBL model increases. It is interesting to note that the PBL height obtained from LES does not increase and even decrease when the shear is weak $\left(U_{g}=5 \mathrm{~m} \mathrm{~s}^{-1}\right)$. This might be caused by the weakening of the large-scale convective eddies, which plays an important role in the entrainment, in the presence of the background wind. This effect is not usually taken into account in the PBL models.

\subsection{SENSITIVITY OF EACH MODIFICATION IN THE NEW PBL MODEL}

Figures 11, 12 and 13 compare the results of profiles from the PBL models, NEW, NEW0, and NEW1, for the same cases as in Figures 6, 7 and 8. The profiles from the three models are almost indistinguishable from each other except at a few points. The neglect of the non-local momentum mixing in NEW1 gives stronger shear in the mean velocity profile, as in the case of the TM model (Figure 8). Constant values of $w_{s}$ and $P r$ are also found to lead to weak stable stratification throughout the boundary layer in free convection, also as in the case of the TM model (Figure 6). Meanwhile, these modifications hardly affect the heat flux profile and the growth of the PBL height.

According to (27), $\mathrm{Pr}$ increases slowly with $z$ within the PBL. On the other hand, $w_{s}$, given by (25), also increases slowly with $z$, and thus cancels out the variation of $\mathrm{Pr}^{-1}$ in the calculation of $K_{h}\left(=P r^{-1} k w_{s} z(1-z / h)^{2}\right)$. As a result, $K_{h}$ in the new PBL model remains comparable to the case of the TM model. For example, in free convection, where the vertical variations of $w_{s}$ and $\operatorname{Pr}$ are the 
(a)

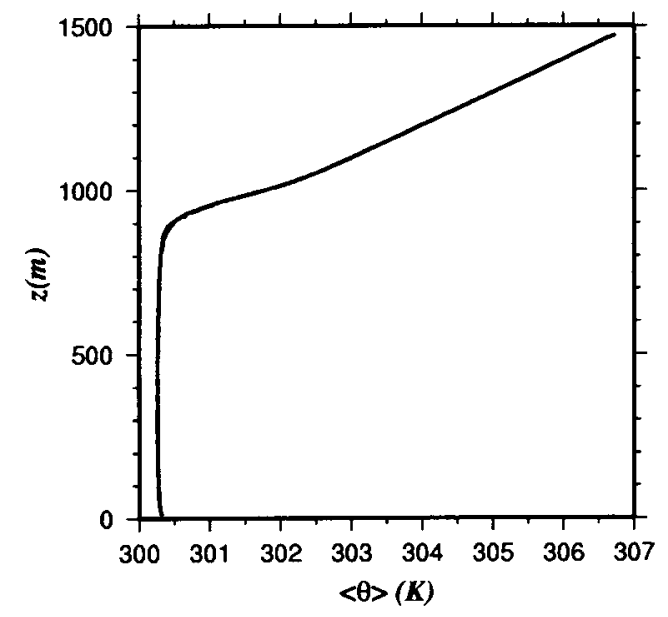

(b)

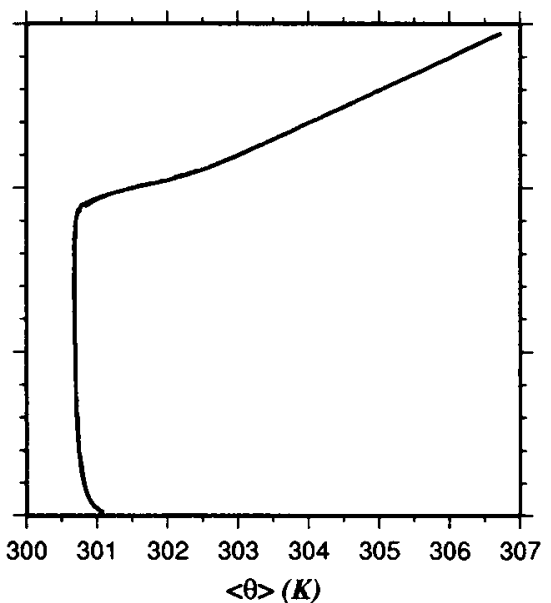

(c)

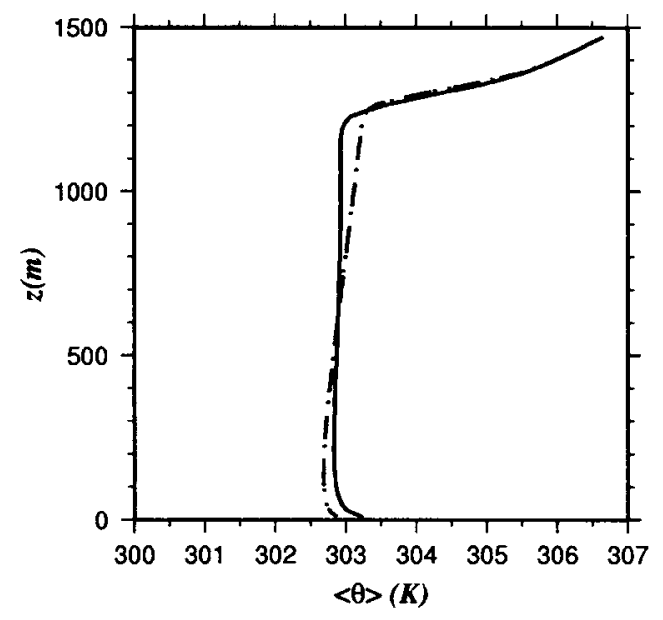

Figure 11. The profiles of potential temperature at $t=6000 \mathrm{~s}$ (Solid lines are from the new PBL model (NEW), dashed lines are from NEW0, and dotted lines are from NEW1.) (The results from NEW0 and NEW1 are overlapped.) (a) A3, (b) B2, (c) C0. When the results from NEW0 and NEW1 coincide, they appear as a dot-dashed line, as in (c), and when all three results coincide, they appear as one solid line, as in (a) and (b).

greatest, $\operatorname{Pr} / \operatorname{Pr}_{0}$ increases from 1 to 3.8 and $w_{s} / w_{s 0}$ increases from 1 to 2.1 . The variations are much less in other cases.

The influence of non-local momentum mixing is also insignificant, because the entrainment is dominated by convective eddies in most cases, so the difference in the intensity of shear in the PBL does not affect the results very much. On the other hand, if the PBL becomes dominated by shear, the difference between the cases with and without non-local momentum mixing becomes smaller. 
(a)

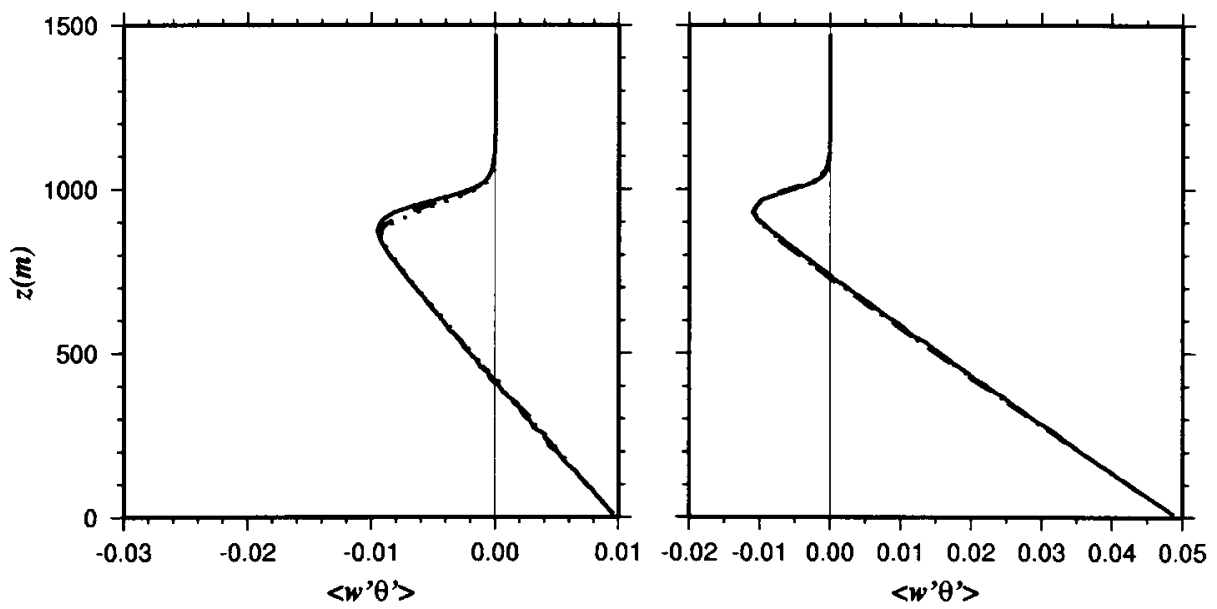

(c)

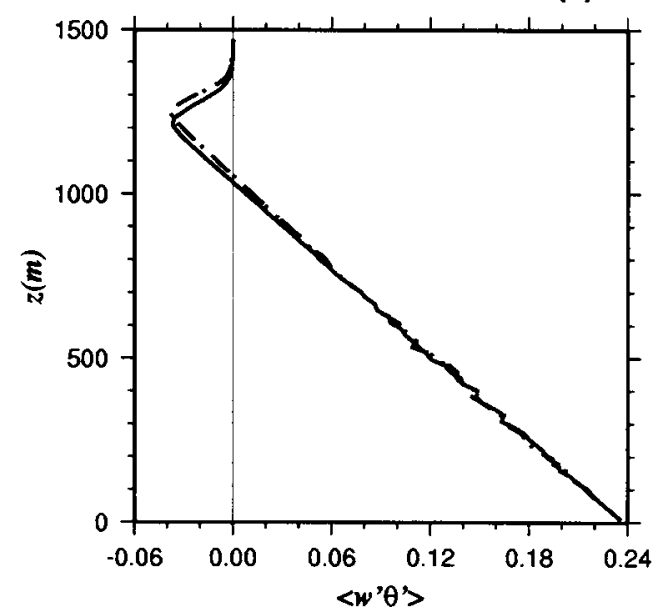

Figure 12. The profiles of heat flux (units of $\mathrm{K} \mathrm{m} \mathrm{s}^{-1}$ ) at $t=6000 \mathrm{~s}$ (Solid lines are from the new PBL model (NEW), dashed lines are from NEW0, and dotted lines are from NEW1.) (The results from NEW0 and NEW1 are overlapped.) (a) A3, (b) B2, (c) C0. When the results from NEW0 and NEW1 coincide, they appear as a dot-dashed line.

From this result, we can infer that the most important element for the improvement in the prediction of the growth of the PBL height is the explicit representation of the entrainment rate in the heat and momentum flux profiles. 
(a)

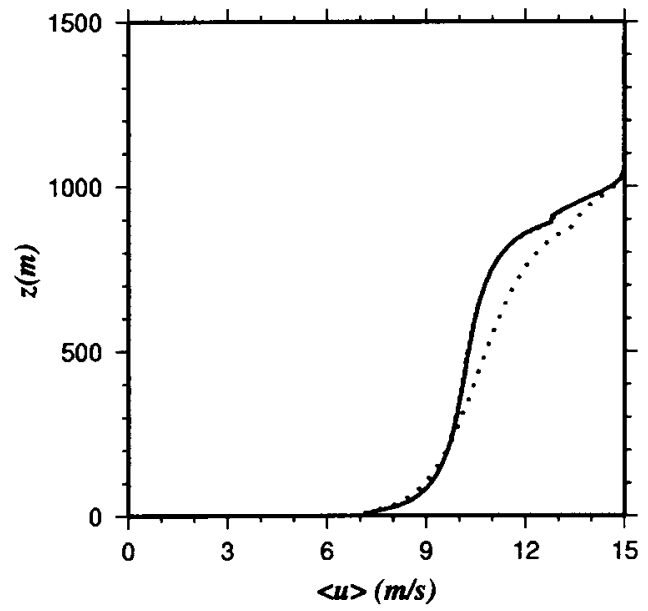

(b)

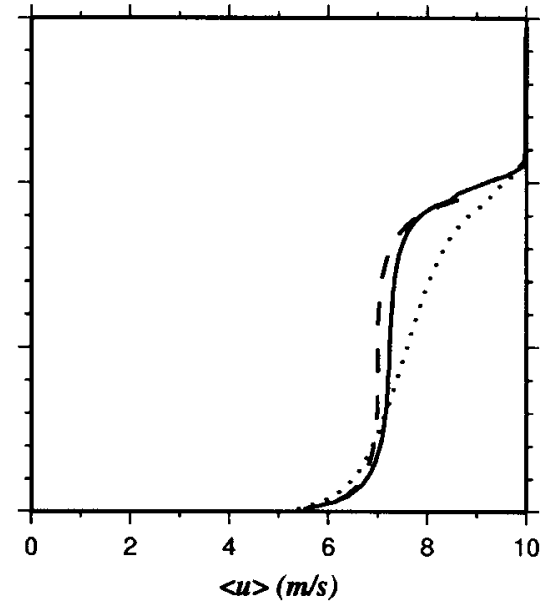

Figure 13. The profiles of mean velocity in the $x$-direction at $t=6000 \mathrm{~s}$ (Solid lines are from the new PBL model (NEW), dashed lines are from NEW0, and dotted lines are from NEW1.) (a) A3, (b) B2.

\section{Summary}

We suggest an improvement of the K-profile model of Troen and Mahrt (1986), based on the analysis of LES data and on the consistency with theoretical characteristics of the PBL. The new model involves three major modifications of the TM model; that is, the explicit representation of the entrainment rate in the heat and momentum flux profiles, the inclusion of non-local momentum mixing, and the vertically varying Prandtl number and velocity scale. The comparison between the TM model and the new PBL model is summarized in Table II.

The results from both the new PBL model and the TM model were compared with LES data. The growth of the PBL height in the TM model was found to be too strong in the PBL with strong shear and too weak in the convection-dominated PBL. Moreover, inadequate prediction of the PBL height causes the TM model to give unrealistic heat flux profiles in the corresponding cases. Too strong shear in the velocity profile and weak stable stratification throughout the boundary layer were observed in the TM model. These situations are significantly improved in the new PBL model. We also investigated how each of the three factors affects the results. We found that the explicit representation of the entrainment rate is the most critical for the improvement, whereas the effects of the other factors, the inclusion of nonlocal momentum mixing, and the vertically varying Prandtl number and velocity scale, are insignificant. 


\section{Acknowledgement}

We are grateful to Prof. T.Y. Lee of Yonsei University for his interest and critical comments. This study has been supported by National Research Laboratory Program from the Ministry of Science and Technology, Cooperative Research under the Korean-German Science Program, SRC Program from KOSEF, and by BK21 Project from the Ministry of Education, Korea.

\section{References}

Abdella, K. and McFarlane, N.: 1997, 'A New Second-Order Closure Scheme for the Planetary Boundary Layer', J. Atmos. Sci. 54, 1850-1867.

Asselin, R.: 1972, 'Frequency Filter for Time Integrations', Mon. Wea. Rev. 100, 487-490.

Ayotte, K. W., Sullivan, P. P., Andrén, A., Doney, S. C., Holtslag, A. A., Large, W. G., McWilliams, J. C., Moeng, C. H., Otte, M. J., Tribbia, J. J., and Wyngaard, J. C.: 1996, 'An Evaluation of Neutral and Convective Planetary Boundary-Layer Parameterizations Relative to Large Eddy Simulations', Boundary-Layer Meteorol. 79, 131-175.

Ball, F. K.: 1960, 'Control of Inversion Height by Surface Heating', Quart. J. Roy. Meteorol. Soc. 44, 2823-2838.

Brown, A. R.: 1996, 'Evaluation of Parameterization Schemes for the Convective Boundary Layer Using Large-Eddy Simulation Results', Boundary-Layer Meteorol. 81, 167-200.

Brown, A. R. and Grant, A. L. M.: 1997, 'Non-Local Mixing of Momentum in the Convective Boundary Layer', Boundary-Layer Meteorol. 84, 1-22.

Businger, J. A., Wyngaard, J. C., Izumi, Y., and Bradley, E. F.: 1971, 'Flux-Profile Relationships in the Atmospheric Surface Layer', J. Atmos. Sci. 28, 181-189.

Chrobock, G., Raasch, S., and Etling, D.: 1992, 'A Comparison of Local and Non-Local Turbulence Closure Methods for the Case of a Cold Air Outbreak', Boundary-Layer Metorol. 58, 69-90.

Deardorff, J. W.: 1966, 'The Counter Gradient Heat Flux in the Lower Atmosphere and in the Laboratory', J. Atmos. Sci. 23, 503-506.

Deardorff, J. W.: 1979, 'Prediction of Convective Mixed-Layer Entrainment for Realistic Capping Inversion Structure', J. Atmos. Sci. 36, 205-236.

Deardorff, J. W.: 1980, 'Stratocumulus-Capped Mixed Layers Derived from a Three-Dimensional Model', Boundary-Layer Meteorol. 18, 495-527.

Deardorff, J. W., Willis, G. E., and Stockton, B. H.: 1980, 'Laboratory Studies of the Entrainment Zone of a Convective Mixed Layer', J. Fluid Mech. 100, 41-64.

Driedonks, A. G. M.: 1982, 'Models and Observations of the Growth of the Atmospheric Boundary Layer', Boundary-Layer Meteorol. 23, 283-306.

Frech, M and Mahrt, L.: 1995, 'A Two-Scale Mixing Formulation for the Atmospheric Boundary Layer', Boundary-Layer Meteorol. 73, 91-104.

Holtslag, A. A. M. and Boville, B. A.: 1993, 'Local Versus Non-Local Boundary Layer Diffusion in a Global Climate Model', J. Climate 6, 1825-1842.

Holtslag, A. A. M. and Moeng, C. H.: 1991, 'Eddy Diffusivity and Countergradient Transport in the Convective Boundary Layer', J. Atmos. Sci. 48, 1690-1698.

Hong, S. Y. and Pan, H. L.: 1996, 'Non-Local Boundary Layer Vertical Diffusion in a Medium-Range Forecast Model', Mon. Wea. Rev. 124, 2322-2339.

Lenschow, D. H., Wyngaard, J. C., and Pennell, W. T.: 1980, 'Mean Field and Second Moment Budget in a Baroclinic, Convective Boundary Layer', J. Atmos. Sci. 37, 1313-1326. 
Lock, A. P.: 1998, 'The Parameterization of Entrainment in Cloudy Boundary Layers', Quart. J. Roy. Meteorol. Soc. 124, 2729-2753.

Lock, A. P., Brown, A. R., Bush, M. R., Martin, G. M. and Smith, R. N. B.: 2000, 'A New Boundary Layer Mixing Scheme. Part I: Scheme Description and Single-Column Model Tests', Mon. Wea. Rev. 128, 3187-3199.

Lüpkes, C. and Schlünzen, K. H.: 1996, 'Modeling the Arctic Convective Boundary-Layer with Different Turbulence Parameterizations', Boundary-Layer Meteorol. 79, 107-130.

Mahrt, L., Hearld, R. C., Lenschow, D. H., Stankov, B. B., and Troen, I.: 1979, 'An Observational Study of the Nocturnal Boundary Layer', Boundary-Layer Meteorol. 17, 247-264.

Mellor, G. L. and Yamada, T.: 1982, 'Development of a Turbulence Closure Model for Geophysical Fluid Problems', Rev. Geophys. Space Phys. 20, 851-875.

Moeng, C. H. and Sullivan, P. P.: 1994, 'A Comparison of Shear and Buoyancy-Driven Planetary Boundary Layer Flows', J. Atmos. Sci. 51, 999-1022.

Panofsky, H. M. and Dutton, J. A.: 1984, Atmospheric Turbulence: Models and Methods for Engineering Applications, Wiley \& Sons, 397 pp.

Piacsek, S. A. and Williams, G. P.: 1970, 'Conservation Properties of Convection Difference Schemes', J. Appl. Meteorol. 9, 856-861.

Raasch, S. and Etling, D.: 1991, 'Numerical Simulation of Rotating Turbulent Thermal Convection', Beitr. Phys. Atmosph. 64, 185-199.

Raasch, S. and Etling, D.: 1998, 'Modelling Deep Ocean Convection: Large Eddy Simulation in Comparison with Laboratory Experiments', J. Phys. Oceanog. 28, 1786-1802.

Raasch, S. and Harbusch, G.: 2001, 'An Analysis of Secondary Circulations and their Effects Caused by Small-Scale Surface Inhomogeneities Using Large-Eddy Simulation', Boundary-Layer Meteorol. 101, 31-59.

Raasch, S. and Schröter, M.: 2001, 'PALM - A Large Eddy Simulation Model Performing on Massively Parallel Computers', Z. Meteorol. 10, 363-372.

Schröter, M., Bange, J., and Raasch, S.: 2000, 'Simulated Airborne Flux Measurements in a LES Generated Convective Boundary Layer', Boundary-Layer Meteorol. 95, 437-465.

Sorbjan, Z.: 1996, 'Numerical Study of Penetrative and "Solid Lid" Nonpenetrative Convective Boundary Layers', J. Atmos. Sci. 53, 101-112.

Stull, R. B.: 1976, 'The Energetics of Entrainment across a Density Interface', J. Atmos. Sci. 33, 1260-1267.

Stull, R. B.: 1984, 'Transilient Turbulence Theory. Part I: The Concept of Eddy Mixing across Finite Distances', J. Atmos. Sci. 41, 3351-3367.

Stull, R. B.: 1988, An Introduction to Boundary Layer Meteorology, Kluwer Academic Publishers, Dordrecht, $666 \mathrm{pp}$.

Therry, G. and Lacarrére, P.: 1983, 'Improving the Eddy Kinetic Energy Model for Planetary Boundary Layer Description', Boundary-Layer Meteorol. 25, 63-88.

Troen, I. and Mahrt, L.: 1986, 'A Simple Model of the Atmospheric Boundary Layer: Sensitivity to Surface Evaporation', Boundary-Layer Meteorol. 37, 129-148.

vanZanten, M. C., Duynkerke, P. G., and Cuijpers, W. M.: 1999, 'Entrainment Parameterization in Convective Boundary Layers', J. Atmos. Sci. 56, 813-828.

Vogelezang, D. H. P. and Holtslag, A. A. M.: 1996, 'Evaluation and Model Impacts of Alternative Boundary-Layer Height', Boundary-Layer Meteorol. 81, 245-269.

Wetzel, P. J.: 1982, 'Toward Parameterization of the Stable Boundary Layer', J. Appl. Meteorol. 21, 7-13.

Wittich, K. P. and Roth, R.: 1984, 'A Case Study of Non-Local Wind and Temperature Profiles over the Inhomogeneous Terrain of Northern Germany with Some Considerations of Turbulent Fluxes', Boundary-Layer Meteorol. 28, 169-186.

Zeman, O. and Tennekes, H.: 1977, 'Parameterization of the Turbulent Kinetic Energy Budget at the Top of the Daytime Boundary Layer', J. Atmos. Sci. 34, 111-123. 
